\title{
Pengaruh Bimbingan Kelompok Teknik Modeling Simbolik Terhadap Perkembangan Akhlak Siswa
}

\author{
Triyani Widyastuti ${ }^{1}$, Anwar Sutoyo ${ }^{2}$ \\ 1,2 Universitas Negeri Semarang
}

*Corresponding author, e-mail: triyaniwys@gmail.com

\begin{abstract}
Abstrak. This study was conducted based on the phenomenon that occurs in fifth grade of SDN 03 Sumurjomblangbogo which shows a low student moral development equality the messenger of Allah SWT, Rasulullah SAW, fellow human beings, created alone and in a calm environment. The purpose of this study was to prove whether or not the influence of group guidance with symbolic modeling techniques on student moral development. The type of this study was one-group experimental pre-test post-test design. This study was conducted in eight meetings with 10 students as a subject. The technique of data analysis used descriptive percentage analysis and wilcoxon test. This study showed that there was a change in the level of moral development of students before and after participating in group guidance services with symbolic modeling techniques that increased by an average $14.3 \%$ from the initial results during the pretest of $62.5 \%$ to $76.8 \%$ at post-test. Additionally, data obtained from wilcoxon pairs match with n-10 significant $5 \%$ obtained with thitung $<$ ttabel $(0<8)$ or Ho is rejected and $\mathrm{Ha}$ is accepted. This shows that the group guidance services with symbolic modeling techniques affect the moral development in fifth grade students of SDN 03 Sumurjomblangbogo.
\end{abstract}

Keyword: Group Guidance, Symbolic Modeling, Moral Development.

\section{Pendahuluan}

Perkembangan akhlak pada usia sekolah khususnya Sekolah Dasar sekarang ini kurang mendapatkan perhatian dalam membentuk karakteristik dan perkembangan siswa sesuai dengan usia perkembangannya (Sudjana, 2010). Masalah akhlak adalah suatu yang menjadi perhatian dimana saja, karena kerusakan akhlak seseorang akan mengganggu ketenteraman orang lain. Di negara kita tercinta ini sudah banyak orang yang rusak akan akhlak/moralnya terbukti banyak pejabat yang korup dan ini jelas merugikan negara. Dengan demikian masalah akhlak harus diperhatikan. Terutama dari kalangan pendidik, alim ulama, pemuka masyarakat dan orang tua (Huda, 2018). Adapun contoh kasus dari hasil penelitian Irawan (2012) kemerosotan akhlak dapat terlihat pada gejala perilaku yang tidak terkontrol, cenderung kasar, rendahnya perilaku sopan santun, dan tingkat perkembangan sosial yang masih rendah pada siswa SDN 60 Salubattang Kota Pallopo. Untuk meningkatkan akhlak siswa di SDN 60 Salubattang Kota Pallopo terbukti penerapan metode bercerita mampu meningkatkan siswa dalam memahami ajaran islam dan diperoleh hasil adanya perubahan-perubahan yang signifikan dalam kehidupan sehari-hari, terlihat adanya perubahan sikap dan perilaku siswa yang mengarah pada hal-hal positif. Lebih lanjut Huda (2018) mengatakan bahwa pendidikan akhlak harus ditanamkan sejak anak masih dalam kandungan agar nantinya terbiasa dengan hal-hal yang baik. Hidupnya mempunyai pedoman baik di rumah, di sekolah maupun di lingkungan masyarakat yang dihadapinya. orang tua atau pendidik merupakan faktor penting keteladanan dalam hal baik buruknya anak. Setiap orang 
tua hendaknya waspada terhadap ancaman arus globalisasi yang akan menggerus kepribadian anak. Perkembangan akhalak siswa dipengaruhi dari dalam diri dan luar (masyarakat) serta di dalam lingkungan tempat siswa berkembang sangat kompleks. Menurut Ibnu Miskawaih dalam Mansur (2007) akhlak adalah keadaan jiwa seseorang yang mendorongnya untuk melakukan perbuatan-perbuatan tanpa melalui pertimbangan pikiran lebih dulu. Akhlak yang baik adalah tujuan setiap agama, karena dengan akhlak yang baik akan tercipta kebaikan dan kedamaian dalam masyarakat maupun dalam diri sendiri. Oleh sebab itu pendidikan akhlak harus mulai diterapkan kepada anak, sejak anak masih berusia sekolah dasar, dan orang tua harus bertanggung jawab atas pendidikan tersebut (Huda, 2018).

Hasil observasi awal pada bulan Agustus 2020 di SDN 03 Sumurjomblangbogo, ditemukan fenomena siswa yang memiliki akhlak seperti ketika melihat guru pura-pura tidak melihat dan cuek, saat kegiatan belajar siswa tidak memperhatikan apa yang dijelaskan oleh guru melainkan asik melakukan kegiatan lain, mengobrol dengan teman sebangku, mengejek sesama teman serta suka menjahili teman. Selain itu, hasil wawancara dengan guru SDN 03 Sumurjomblangbogo diketahui bahwa siswa dalam tingkat perkembangan akhlaknya masih rendah. Para siswa masih banyak yang tidak melakukan kewajibannya sesuai dengan peraturan yang di wajibkan bagi seorang siswa. Contohnya cara berpakaian, cara berbicara antar teman di sekolah, melanggar peraturan yang dibuat sekolah dan lain sebagainya. Akhlak tersebut tidak mencerminkan akhlak yang terpuji di usia perkembangannya. Akhlak diperlukan supaya mereka dapat belajar dan berperilaku baik pada lingkungan dimana ia berada. Oleh karena itu, akhlak merupakan faktor penting dan menjadi perhatian bersama, terutama dalam perkembangan pribadi-sosial anak untuk mengatasi fenomena-fenomena kemerosotan akhlak. Untuk menetapkan indikator atau acuan perkembangan akhlak siswa di SDN 03 Sumurjomblangbogo. Indikator tersebut terdiri dari Akhlak terhadap Allah SWT, Rasulullah SAW, sesama manusia, diri sendiri dan lingkungan.

Masa anak Sekolah Dasar (SD) adalah masa yang tepat untuk membina perkembangan akhlak karena pada masa ini anak telah mengenal lingkungan luar yang memungkinkan anak mampu mencontoh dan mempelajari hal-hal negatif yang dapat merusak bila tidak diarahkan. Dalam pelaksanaan pendidikan di sekolah untuk bisa berproses pada perkembangan akhlak yang bermutu maka siswa perlu diarahkan. Sehingga siswa menyadari bahwa dengan memiliki akhlak yang baik akan mempermudah kehidupan dirinya sendiri. Pendidikan sebagai upaya membimbing siswa untuk mencapai kematangan berfikir dan bertingkah laku dengan tujuan agar anak cukup baik dalam melaksanakan tugas perkembangannya.

Kaitannya dengan proses pendidikan di sekolah, ini merupakan tugas guru termasuk guru Bimbingan dan Konseling melalui layanan bimbingan dan konseling karena sebagaimana disebutkan bahwa salah satu tujuan bimbingan dan konseling adalah membantu mengembangkan potensi siswa secara optimal. Bantuan yang diberikan kepada siswa agar efektif harus mempertimbangkan relevansi antara jenis layanan bimbingan dengan masalah yang dialami oleh siswa. Bantuan yang tepat akan memperoleh perubahan-perubahan tingkah laku yang diharapkan (Wahyuni, 2013). Peran guru bimbingan dan konseling dalam mengembangkan akhlak siswa juga tak kalah penting. Karena, peran guru bimbingan dan konseling disini adalah menindaklanjuti masalah yang dihadapi siswa dan juga sebagai media siswa untuk menyampaikan keluh kesahnya dengan tenang dan tanpa ada intimidasi. Menurut Bonebrake dan Rogers dalam Gladding, peran 
ideal konselor sekolah menengah adalah menyediakan konseling individual, kelompok, system dukungan bersama, konsultasi guru, penilaian murid, konsultasi orang tua dan evaluasi layanan bimbingan (Gladding, 2012). Pendekatan konseling adalah sebuah pendekatan dalam menangani tingkah laku siswa negatif yang bertujuan untuk mengubah tingkah laku negatif siswa menjadi tingkah laku positif dengan usaha-usaha tertentu (Mu'awanah dan Rifa, 2012). Konseling sekolah mempunyai tanggung jawab untuk memberikan pelayanan agar siswa memperoleh kesejahteraan lahiriah dan batiniah dalam proses pendidikan, sehingga dapat mencapai tujuan yang diharapkan, selain itu konselor sekolah biasanya terlibat dalam pelajaran dan penempatan kelas yang tepat bagi para siswa sesuai dengan kebutuhan dan kemampuan siswa (Gibson dan Marianne, 2011).

Salah satu strategi bimbingan yang dapat memfasilitasi siswa untuk mengembangkan dirinya dalam menciptakan tingkah laku baru yang positif yakni strategi bimbingan kelompok. Layanan bimbingan kelompok terselenggara dengan memanfaatkan dinamika kelompok untuk mencapai tujuan layanan bimbingan (Mugiarso, 2011). Secara umum layanan bimbingan kelompok bertujuan untuk mengembangkan kemampuan bersosialisasi, khususnya kemampuan berkomunikasi para peserta bimbingan. Sedangkan secara khusus, layanan bimbingan kelompok bertujuan untuk mendorong untuk mengembangkan perasaan, pikiran, persepsi, wawasan dan sikap yang menunjang perwujudan tingkah laku yang lebih efektif yaitu peningkatan kemampuan berkomunikasi pada siswa baik verbal maupun non verbal (Tohirin, 2015).

Individu dapat belajar dengan hanya mengamati perilaku individu lain. Sedangkan individu yang dijadikan suatu objek pengamatan disebut sebagai model (Previn et al., 2012). Selanjutnya Corey (2013) menjelaskan modeling simbolik merupakan cara atau prosedur yang dilakukan dengan menggunakan media seperti film, video, buku panduan, dan lain sebagainya dengan cara mendemonstrasikan perilaku yang dikehendaki atau dimiliki klien. Modeling simbolik ini dikembangkan untuk perorangan maupun kelompok.

Layanan bimbingan kelompok dapat dijadikan salah satu pilihan untuk memberikan bantuan pada siswa. Di dalam bimbingan kelompok siswa dapat membahas topik perkembangan akhlak, berdikusi bersama-sama dan melakukan aktivitas terkait akhlak. Bimbingan kelompok dengan teknik modeling simbolik menjadi pilihan dalam layanan karena mempertimbangkan ajaran akhlak mulia Rasulullah SAW. Teknik modeling ini merupakan pembelajaran pada siswa dengan menggunakan media berbasis audio-visual yaitu berupa video yang menyajikan contoh akhlak dan tingkah laku berpotensi sebagai sumber model perkembangan akhlak dimana model yang ditunjukan dari akhlak mulia nabi Muhammad Saw. Kita dapat meneladani akhlak mulia Rasulullah SAW, karena Rasulullah di utus ke muka bumi membawa misi untuk menyempurnakan akhlak manusia (Sylviyanah, 2012).

Berdasarkan latar belakang di atas, maka peneliti tertarik untuk melakukan penelitian pengaruh bimbingan kelompok dengan teknik modeling simbolik terhadap perkembangan akhlak siswa kelas V SDN 03 Sumurjomblangbogo

\section{Metode}

Metode penelitian yang digunakan dalam penelitian adalah eksperimen (pre-experimental design). Metode yang digunakan adalah The One Group Pre-Test Post-Test Design. Penelitian one-group pretest-postest adalah penelitian eksperimen dengan melakukan pre-test sebelum diberi perlakuan 
untuk dijadikan perbandingan dengan setelah diberi perlakuan (Sugiyono, 2016). Kemudian hasil dari pre-test (sebelum diberi perlakuan) akan dibandingkan dengan hasil post-test (setelah diberi perlakuan).

Populasi dalam penelitian ini 35 siswa kelas V SDN 03 Sumurjomblangbogo. Pengambilan sampel sebanyak 10 orang dengan menggunakan teknik purposive sampling. Tahapan yang dilalui dalam penelitian adalah penyusunan kisi-kisi instrument, uji ahli, revisi, uji coba instrumen, melakukan revisi terhadap instrumen yang belum valid, melakukan pre-tets, treatmen sebanyak enam kali dan terakhir post-test untuk mengetahui perbedaan sebelum dan setelah diberikan layanan bimbingan kelompok teknik modeling simbolik.

Instrumen yang digunakan dalam penelitian ini meliputi observasi dan wawancara yang terdiri atas 25 item pernyataan dengan empat pilihan jawaban. Alat pengumpulan data yang digunakan adalah lembar observasi dan wawancara dengan penilaian menggunakan tipe numerical rating scale. Aspek penilaian diberikan angka dengan skala 1-4. Tiap-tiap angka memiliki kriteria-kriteria tertentu, angka 1 jika frekuensinya tidak pernah, 2 jika kadang-kadang, 3 jika sering, 4 jika selalu. Indikator dari skala ini adalah akhlak terhadap Allah, akhlak terhadap Rassulullsh, akhlak terhadap sesama manusia, akhlak terhadap diri sendiri, akhlak terhadap lingkungan. Penelitian ini menggunakan teknik modeling simbolik dengan cara menampilkan video kisah nabi Muhammad SAW. Untuk uji validitasnya menggunakan rumus product moment sedangkan untuk uji reliabilitas menggunakan rumus alpha. Dalam penelitian ini hipotesis yang diajukan adalah layanan bimbingan kelompok dengan teknik modeling simbolik berpengaruh terhadap perkembangan akhlak siswa kelas V SDN 03 Sumurjomblangbogo. Uji hipotesis menggunakan uji wilcoxon.

\section{Hasil dan Diskusi}

Berdasarkan Tabel 1, hasil distribusi frekuensi pre-test dan post-test yang diperoleh peneliti sebelum dan sesudah diberikan treatment menunjukan tingkat perkembangan akhlak siswa sebagai berikut.

Tabel 1. Hasil Distribusi Frekuensi Pre-test dan Post-test Sampel

\begin{tabular}{cccccc}
\hline \multirow{2}{*}{ Interval } & \multicolumn{2}{c}{ Siswa Kelas V } & \\
& Pre Test & \multicolumn{2}{c}{ Post Test } & Kategori \\
& F & $\%$ & F & $\%$ & \\
\hline $81,56 \%-100 \%$ & 2 & $20 \%$ & 4 & $40 \%$ & Sangat Tinggi \\
$62,51 \%-81,55 \%$ & 4 & $40 \%$ & 6 & $60 \%$ & Tinggi \\
$43,76 \%-62,50 \%$ & 4 & $40 \%$ & 0 & $0 \%$ & Rendah \\
$25,00 \%-43,75 \%$ & 0 & $0 \%$ & 0 & $0 \%$ & Sangat rendah \\
Total & 10 & $100 \%$ & 10 & $100 \%$ & \\
\hline
\end{tabular}

Berdasarkan tabel 1 dapat diketahui bahwa frekuensi tingkat perkembangan akhlak siswa di kelas eksperimen sebelum dan setelah mendapat treatment bervariasi ada yang yang memperoleh kategori rendah, tinggi, dan sangat tinggi. Dari hasil pre-test maka dapat dipaparkan bahwa layanan bimbingan kelompok teknik modeling simbolik terhadap 10 responden terdapat 4 responden termasuk dalam kategori rendah dengan persentase 40\%, 4 responden termasuk dalam kategori 
tinggi dengan presentase $40 \%$ dan 2 responden termasuk dalam kategori sangat tinggi. Perbedaan yang terjadi sudah menunjukan tingkat yang cukup signifikan, karena terdapat selisih pada jumlah frekuensi siswa dan hasil persentasenya yang menunjukkan kategori sangat tinggi, tinggi dan rendah.

Sedangkan dari hasil post-test bahwa perkembangan akhlak siswa pada kelompok eksperimen mengalami peningkatan yang cukup signifikan, yaitu dengan frekuensi 4 responden termasuk dalam kategori sangat tinggi dengan persentase $40 \%$ dan 6 responden termasuk dalam kategori tinggi. Setelah mengetahui penjelasan dari hasil pre-test dan post-test yang telah dilaksanakan maka dapat diketahui bahwa kelompok eksperimen mengalami peningkatan sesudah mendapatkan perlakuan (treatment). Kemudian untuk mengetahui tingkat perkembangan akhlak siswa sebelum dan sesudah diberikan treatment layanan bimbingan kelompok dengan teknik modeling simbolik, peneliti menggunakan analisis deskriptif. Berikut ini adalah hasil analisis deskriptif seluruh responden secara keseluruhan, dapat di lihat pada tabel 2.

Tabel 2. Hasil Perbandingan Pre-test dan Post-test

\begin{tabular}{|c|c|c|c|c|c|c|c|c|}
\hline \multirow{2}{*}{ No } & \multirow{2}{*}{ Responden } & \multicolumn{3}{|c|}{ Pre-Test } & \multicolumn{3}{|c|}{ Post-Test } & \multirow{2}{*}{ Pening-katan } \\
\hline & & $\Sigma$ & $\%$ & Kategori & $\Sigma$ & $\%$ & Kategori & \\
\hline 1 & $\mathrm{R}-1$ & 56 & 56 & Rendah & 72 & 72 & Tinggi & $16 \%$ \\
\hline 2 & $\mathrm{R}-2$ & 63 & 63 & Tinggi & 79 & 79 & Tinggi & $16 \%$ \\
\hline 3 & $\mathrm{R}-3$ & 69 & 69 & Tinggi & 83 & 83 & Sangat Tinggi & $14 \%$ \\
\hline 4 & $\mathrm{R}-4$ & 66 & 66 & Tinggi & 74 & 74 & Tinggi & $8 \%$ \\
\hline 5 & $\mathrm{R}-5$ & 70 & 70 & Tinggi & 83 & 83 & Sangat Tinggi & $13 \%$ \\
\hline 6 & R-6 & 44 & 44 & Rendah & 71 & 71 & Tinggi & $27 \%$ \\
\hline 7 & $\mathrm{R}-7$ & 82 & 82 & Sangat Tinggi & 85 & 85 & Sangat Tinggi & $3 \%$ \\
\hline 8 & $\mathrm{R}-8$ & 83 & 83 & Sangat Tinggi & 84 & 84 & Sangat Tinggi & $1 \%$ \\
\hline 9 & R-9 & 47 & 47 & Rendah & 68 & 68 & Tinggi & $21 \%$ \\
\hline 10 & $\mathrm{R}-10$ & 45 & 45 & Rendah & 69 & 69 & Tinggi & $24 \%$ \\
\hline \multicolumn{2}{|r|}{ Rata-rata } & 62,5 & 62,5 & Rendah & 76,8 & 76,8 & Tinggi & $14,3 \%$ \\
\hline
\end{tabular}

Pada tabel 2 dapat diketahui bahwa rata-rata tingkat perkembangan akhlak siswa mengalami peningkatan dari yang semula termasuk kategori rendah dengan skor rata-rata 62,5 (62,5\%) menjadi kategori tinggi dengan skor rata-rata 77,5 (77,5\%). Secara lebih jelas peningkatan perkembangan akhlak siswa per indikator yang meliputi akhlak kepada Allah, akhlak kepada Rasulullah, akhlak terhadap sesama manusia, akhlak terhadap diri sendiri dan akhlak terhadap lingkungan sebelum dan setelah diberikan layanan bimbingan kelompok dengan teknik modeling simbolik dapat di lihat pada tabel 3 . 
Tabel 3. Hasil Persentase Skor Berdasarkan Per Indikator

\begin{tabular}{ccccccc}
\hline No & \multicolumn{1}{c}{ Indikator } & $\begin{array}{c}\text { \% Skor } \\
\text { Pre Test }\end{array}$ & Kategori & $\begin{array}{c}\text { \% Skor } \\
\text { Post Test }\end{array}$ & Kategori & $\begin{array}{c}\text { Pening- } \\
\text { katan }\end{array}$ \\
\hline 1. & Akhlak terhadap Allah & 69,37 & Tinggi & 81,25 & Tinggi & $11,88 \%$ \\
2. & Akhlak terhadap Rasulullah & 72,25 & Tinggi & 81,25 & Tinggi & $9 \%$ \\
3. & Akhlak terhadap sesama Manusia & 62,22 & Rendah & 75 & Tinggi & $12,78 \%$ \\
4. & Akhlak terhadap Diri Sendiri & 59,16 & Rendah & 77,08 & Tinggi & $17,92 \%$ \\
5. & Akhlak terhadap Lingkungan & 56,25 & Rendah & 73,75 & Tinggi & $17,5 \%$ \\
\hline & Persentase skor rata-rata & $\mathbf{6 3 , 8 5}$ & Rendah & $\mathbf{7 7 , 6 6}$ & Tinggi & $\mathbf{1 3 , 8 1 \%}$ \\
\hline
\end{tabular}

Berdasarkan tabel 3 diketahui bahwa terjadi peningkatan pada tiap indikator-indikator perkembangan akhlak siswa dengan rata-rata peningkatan sebesar 13,81\%. Penelitian yang telah dilakukan bertujuan untuk mengetahui tingkat perkembangan akhlak siswa sebelum dan setelah diberikan layanan bimbingan kelompok dengan teknik modeling simbolik. Selain itu juga bertujuan untuk membuktikan ada atau tidaknya pengaruh layanan bimbingan kelompok dengan teknik modeling simbolik terhadap tingkat perkembangan akhlak siswa kelas $\mathrm{V}$ SDN 03 Sumurjomblangbogo.

Hasil dari penelitian ini diharapkan dapat memberikan sumbangan konseptual untuk pengembangan ilmu bimbingan dan konseling, khususnya mengenai bimbingan kelompok dengan teknik modeling simbolik dalam meningkatkan perkembangan akhlak siswa. Sehingga dapat dijadikan rujukan maupun acuan dalam meningkatkan mutu dan kualitas layanan bimbingan dan konseling di SD. Selanjutnya, tingkat perkembangan akhlak siswa dapat dipengaruhi dengan adanya pemberian layanan bimbingan kelompok dengan teknik modeling simbolik yang ditunjukan melalui beberapa indikator berupa: akhlak terhadap Allah, akhlak terhadap Rasulullah, akhlak terhadap sesama manusia, akhlak terhadap diri sendiri, dan akhlak terhadap lingkungan. Desmita (2009) menjelaskan bahwa perkembangan akhlak merupakan aturan yang berkaitan dengan apa yang seharusnya dilakukan oleh individu saat berinterkasi dengan individu lain. Sehingga siswa perlu memiliki akhlak yang baik/terpuji supaya mereka dapat belajar dan berperilaku baik pada lingkungan sekitar serta berhasil menjadi pribadi yang lebih baik lagi. Menurut Mansur (2009) seseorang akan menjadi sempurna apabila mempunyai akhlak terpuji serta menjauhi segala akhlak tercela.

Halimah (2017) menjelaskan bahwa macam-macam akhlak berdasarkan sifatnya yaitu: pertama, akhlak terpuji (mahmudah) adalah tingkah laku atau perbuatan-perbuatan yang baik, seperti setia, pemaaf, benar, menepati janji, menundukan diri kepada Allah, adil, sabar, kuat, menghormati tamu, merendah diri, berbuat baik, lemah lembut, berbudi tinggi, merasa cukup dengan yang ada, taat beribadah, menjalankan amanah dan lain sebagainya. kedua akhlak tercela (madæmumab) merupakan tingkah laku atau perbuatan-perbuatan yang buruk, seperti hasad, yakni dengki, suka harta dunia baik halal maupun haram, mengumpat, naminah, bermain judi, riya, kufur, syirik, takabur dan lain sebagainya.

Layanan bimbingan kelompok dapat digunakan untuk menunjang perkembangan pribadi dan perkembangan sosial masing-masing anggota kelompok serta meningkatkan mutu 
kerjasama dalam kelompok guna mecapai aneka tujuan yang bermakna bagi partisipan (Winkel dan Hastuti, 2012). Teknik modeling merupakan proses belajar melalui observasi dengan menambahkan atau mengurangi tingkah laku yang teramati, menggeneralisir berbagai pengamatan sekaligus melibatkan proses kognitif (Komalasari, 2014). Layanan bimbingan kelompok dengan teknik modeling simbolik akan membantu siswa dalam meningkatkan perkembangan akhlak siswa. Peneliti menggunakan teknik modeling simbolik dengan cara menampilkan beberapa video kisah Nabi Muhammad SAW.

Dalam hal ini setiap responden yang menjadi subjek penelitian memiliki perbedaan peningkatan sesuai dengan kemampuan tiap-tiap responden untuk meningkatkan perkembangan akhlak. Adapun hasil dari hasil pre-test dan post-test disajikan dalam grafik berikut:

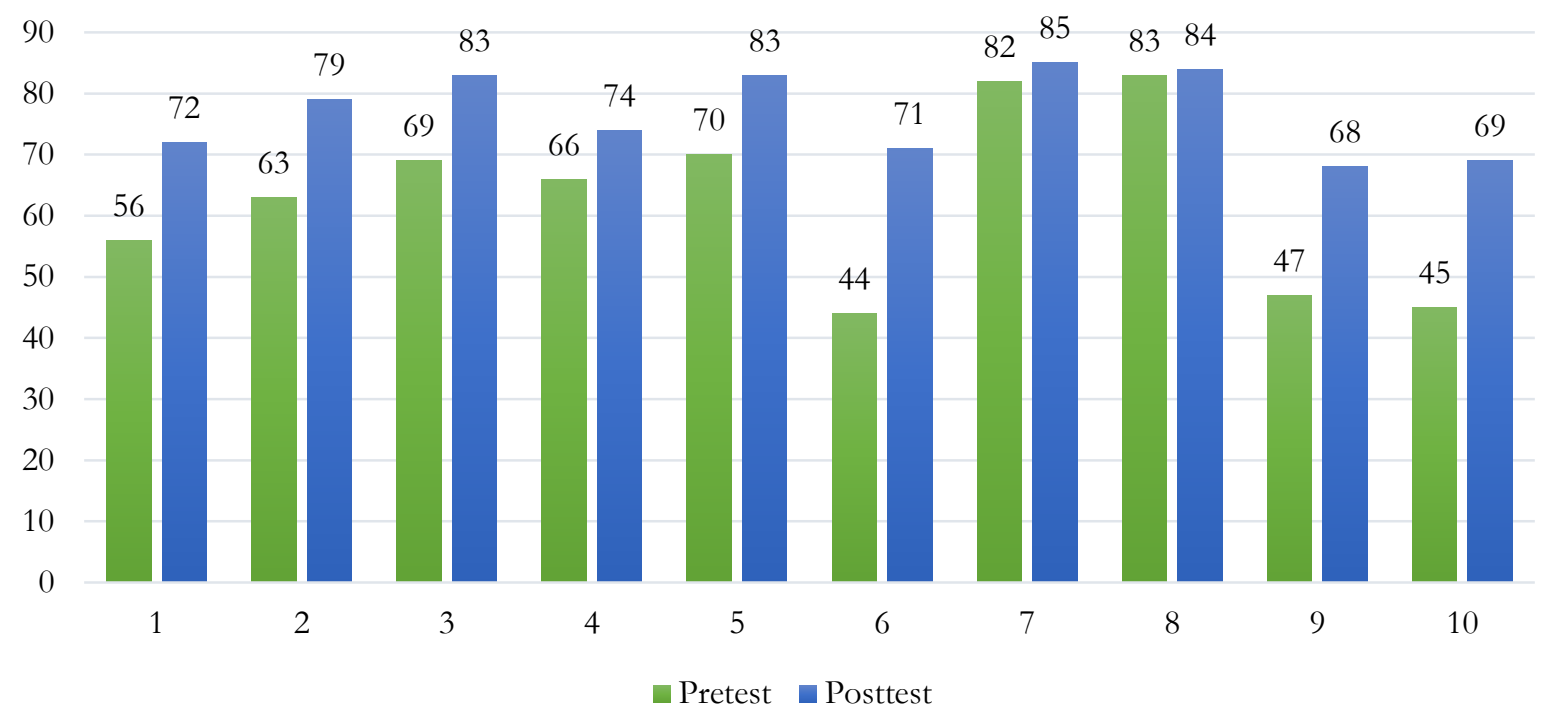

Gambar 1. Grafik Hasil Pre-Test dan Post-Test

Berdasarkan hasil penelitian pada grafik di atas menunjukan bahwa terdapat peningkatan perkembangan akhlak siswa kelas V SDN 03 Sumurjomblangbogo setelah memperoleh perlakuan melalui layanan bimbingan kelompok dengan teknik modeling dari hasil perhitungan data penelitian diketahui bahwa rata-rata tingkat perkembangan akhlak siswa setelah memperoleh layanan bimbingan kelompok dengan teknik modeling lebih tinggi dibandingkan dengan sebelum memperoleh layanan bimbingan kelompok dengan teknik modeling.

Terdapat dua indikator yang mengalami perbedaan peningkatan secara persentase (akhlak terhadap diri sendiri, dan akhlak terhadap Rasulullah) merupakan indikator yang berdiri sesuai ruang lingkup akhlak. Seharusnya siswa yang memiliki akhlak terhadap diri sendiri yang baik maka juga memiliki akhlak terhadap Rasulullah dengan baik. Halimah (2017) menjelaskan bahwa macam-macam akhlak berdasarkan sifatnya salah satunya yaitu: akhlak terpuji (mahmudah) adalah tingkah laku atau perbuatan-perbuatan yang baik, seperti setia, pemaaf, benar, menepati janji, menundukan diri kepada Allah, adil, sabar, kuat, menghormati tamu, merendah diri, berbuat baik, lemah lembut, berbudi tinggi, merasa cukup dengan yang ada, taat beribadah, menjalankan amanah dan lain sebagainya. Sehingga menyebabkan perkembangan akhlak terhadap diri sendiri mampu mengalami peningkatan lebih tinggi di bandingkan dengan keempat indikator. Sedangkan 
pada indikator akhlak terhadap Rasulullah mengalami peningkatan terendah diantara keempat indikator perkembangan akhlak siswa.

Dari hasil analisis secara keseluruhan, terlihat bahwa terdapat perbedaan perkembangan akhlak siswa antara sebelum dan setelah diberikan layanan bimbingan kelompok dengan teknik modeling simbolik. Hal ini dapat dilihat tingkat perkembangan akhlak siswa mengalami peningkatan pada masing-masing indikator. Indikator yang mengalami peningkatan paling tinggi adalah akhlak terhadap diri sendiri dengan persentase peningkatan sebesar $17,92 \%$, sedangkan indikator yang mengalami peningkatan terendah adalah akhlak terhadap Rassulullah dengan persentase peningkatan sebesar 9\%. Hal ini terjadi dikarenakan pada saat pemberian perlakuan yang dilakukan oleh peneliti melalui layanan bimbingan kelompok dengan teknik modeling, dimana layanan bimbingan kelompok dengan teknik modeling efektif untuk meningkatkan akhlak terhadap diri sendiri pada siswa, karena perlakuan tersebut menyediakan media belajar yaitu dengan melihat secara langsung berupa video tentang topik atau masalah yang dihadapi oleh siswa yang diperlukan dalam mengembangkan akhlak terhadap diri sendiri pada diri siswa.

Berdasarkan penelitian yang telah dilaksanakan, dapat disimpulkan bahwa layanan bimbingan kelompok dengan teknik modeling simbolik dapat meningkatkan tingkat perkembangan akhlak siswa. Hasil penelitian ini juga diperkuat dengan hasil analisis data uji wilcoxon diperoleh Thitung $=0$, dan Ttabel $=8$ Sehingga Thitung $<$ Ttabel atau memiliki arti Ho penelitian ditolak dan Ha penelitian di terima, artinya terjadi perbedaan yang signifikan pada perkembangan akhlak siswa antara sebelum dan sesudah diberikan layanan bimbingan kelompok dengan teknik modeling simbolik.

\section{Kesimpulan}

Berdasarkan hasil penelitian tingkat perkembangan akhlak siswa kelas V SDN 03 Sumurjomblangbogo, maka dapat disimpulkan bahwa: 1). Tingkat perkembangan akhlak siswa kelas V SDN 03 Sumurjomblangbogo sebelum mendapatkan layanan bimbingan kelompok dengan teknik modeling simbolik yaitu sebesar $62,5 \%$ dan termasuk dalam kategori rendah, yang ditandai dengan masih rendahnya tingkat akhlak terhadap sesama manusia dan akhlak terhadap diri sendiri. 2) Tingkat perkembangan akhlak siswa kelas V SDN 03 Sumurjomblangbogo setelah mendapatkan layanan bimbingan kelompok dengan teknik modeling simbolik yaitu sebesar 76,8\% dan termasuk dalam kategori tinggi, yang ditandai dengan adanya peningkatan per indikator perkembangan akhlak siswa antara lain: akhlak terhadap Allah, akhlak terhadap Rasulullah, akhlak terhadap sesama manusia, akhlak terhadap diri sendiri, dan akhlak terhadap lingkungan. 3) Bimbingan kelompok dengan teknik modeling simbolik terbukti berpengaruh terhadap tingkat perkembangan akhlak siswa kelas V SDN 03 Sumurjomblangbogo.

\section{Referensi}

Corey, G. (2013). Teori dan Praktek Konseling dan Psikoterapi. Bandung: PT. Refika Aditama.

Desmita. (2009). Psikologi Perkembangan. Bandung: Remaja Rosdakarya. 
Gibson \& Marianne. (2011). Bimbingan dan Konseling (Edisi Indonesia-Edisi ke Tujuh). Yogyakarta: Pustaka Pelajar.

Gladding, T. S. (2012). Konseling: Profesi yang Menyelurub. Jakarta: PT. Indeks Jakarta.

Halimah, H. (2017). Pelaksanaan Pembinaan Akblak Siswa di SD IT Nurul Iman Palembang. (Skripsi, UIN Raden Fatah Palembang).

Huda, H. (2018). Pada Anak Usia Sekolah Dasar ( Studi Kasus Dusun Kedung Sumur Desa Bagon Kec . Puger ). Jurnal Tarlim, 1(1).

Irawan, S. (2012). Implementasi Metode Bercerita Dalam Menanamkan Akhlak Mulia Bagi Peserta didik di SDN 60 Salubattang Kota Palopo. (Tesis: UIN Alauddin Makassar)

Johnson, D. W. \& Johnson, F. P. (2012). Dinamika Kelompok Teori dan Keterampilan. Jakarta: PT. Indeks Jakarta.

Juliawati, D., Yandri, H., Sujadi, E., \& Ahmad, B. (2020). Pemantapan Tauhid Remaja Masjid Melalui Kegiatan Layanan Bimbingan Kelompok. E-Dimas: Jurnal Pengabdian kepada Masyarakat, 11(3), 323-329.

Komalasari. G., Wahyuni. G. \& Karsih. (2014). Teori dan Teknik Konseling. Jakarta: Indeks.

Mansur. (2009). Pendidikan Anak Usia Dini dalam Islam. Yogyakarta: Pustaka Pelajar.

Mugiarso, H. et al. (2011). Bimbingan dan Konseling. Semarang: UPT MKDK UNNES

Putri, M. C., Juliawati, D., Khuryati, A., \& Yandri, H. (2020). Mereduksi Perilaku Menyontek Siswa di Era "Merdeka Belajar" Melalui Layanan Bimbingan Kelompok. Jurnal Penelitian Bimbingan dan Konseling, 5(2).

Sudjana, D. (2010). Pembinaan Akhlak Mulia Pada Sekolah Dasar (Studi Deskriptif Pada Sekolah Dasar Islam Terpadu Nur Al-Rahman). Jurnal Tarbawi, 1(3).

Sugiyono. (2016). Metode Penelitian Pendidikan Pendekatan Kuantitatif, Kualitatif, dan R\&D. Bandung: CV Alfa Beta.

Tohirin. (2015). Bimbingan dan Konseling di Sekolah dan Madrasab (Berbasis Integrasi). Jakarta: PT. Raja Grafindo Persada.

Ulandari, Y., \& Juliawati, D. (2019). Pemanfaatan layanan bimbingan kelompok untuk meningkatkan kecerdasan emosi siswa. Indonesian Journal of Counseling and Development, 1(1), 1 8.

Wahyuni, F. (2013). Jurnal Bimbingan Konseling. Model, Pengembangan Kelompok, Bimbingan Kreativitas, Untuk Mengembangkan, 2(2).

Winkel \& Sri Hastuti. (2012). Bimbingan dan Konseling di Institut dan Pendidikan. Yogyakarta: Media 